\title{
OPERÁRIOS E ESTUDANTES CONTRA A Ditadura: 1968 no BrasiL ${ }^{1}$
}

\author{
Ricardo Antunes ${ }^{2}$ e Marcelo Ridenti ${ }^{3}$
}

\begin{abstract}
RESUMO
0 artigo retoma os acontecimentos de 1968 no Brasil, particularmente no movimento operário e no movimento estudantil. Ambos estavam à esquerda dos movimentos mais tradicionais e propugnavam uma alternativa ao PCB e sua política de moderação, dominante no pré-64, e que revelava seus limites tanto entre os operários quanto entre os estudantes. Mas as lutas estudantis e operárias de 1968 no Brasil não conseguiram tornar viável uma alternativa de massas, exaurindo-se em seu vanguardismo no embate contra a ditadura.

Palavras-chave: 1968. Movimento Operário. Movimento Estudantil. Ditadura Militar.
\end{abstract}

\footnotetext{
${ }^{1}$ Este artigo foi publicado em francês com o título "1968 au Brésil: ouvriers et étudiants contre la dictature". Revista ContreTemps n 22. Paris: éditions Textuel, abril de 2008, p. 40-48. Uma versão abreviada saiu aqui: "1968 no Brasil”. Margem Esquerda, n. 11, maio 2008, p. 43-48.

${ }^{2}$ Professor Titular em Sociologia do Trabalho na Universidade Estadual de Campinas (UNICAMP). Autor de Riqueza e Miséria do Trabalho no Brasil (Boitempo); O Caracol e sua Concha (Boitempo), dentre outros livros. É editor participante e membro do Comitê Editorial das revistas Margem Esquerda (Brasil), Latin American Perspectives (EUA), Proteo (Itália), Herramienta (Argentina), dentre outras publicações.

${ }^{3}$ Professor Titular em Sociologia na Universidade Estadual de Campinas (UNICAMP). Autor de artigos e livros como Em busca do povo brasileiro: artistas da revolução (Record); O fantasma da revolução brasileira (Ed. UNESP); História do Marxismo no Brasil, vols. 5 e 6 (Ed. UNICAMP, com Daniel Aarão Reis et alli).
} 


\begin{abstract}
This article takes up once again the events of 1968 in Brazil, particularly within the labor movement and the student movement. Both were to the left of the more traditional movements and proposed an alternative to the PCB and its policy of moderation, which was dominant in the pre-64 period and revealed its limitations as much among workers as among students. However, the student and labor struggles of 1968 in Brazil were unable to make viable a mass alternative, exhausting itself in its vanguard role in the conflict with the dictatorship.

Keywords: 1968. Labor Movement. Student Movement. Military Dictatorship.
\end{abstract}

\title{
O Contexto da Crise
}

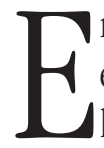

m 1968 presenciamos a era das múltiplas explosões e revoltas: operárias, estudantis, feministas, dos negros, dos movimentos ambientalistas, dos homossexuais, dentre tantas outras formas de levante e descontentamento social e político, naqueles anos que selavam o "fim dos anos dourados".

Mas se tantos movimentos de protesto social e mobilização política agitaram o mundo todo, como o maio libertário dos estudantes e trabalhadores franceses, a "Primavera de Praga" contra o "socialismo real" sob domínio da URSS, o massacre de estudantes no México, as manifestações nos Estados Unidos contra a guerra no Vietnã, as distintas ações revolucionárias armadas em diversos países, os movimentos de contra-cultura, dentre tantos outros exemplos, o Brasil também marcou sua presença neste emblemático ano.

É preciso desde logo dizer que, além da influência dos fatores internacionais e da identidade com movimentos contestadores de outros países, o 1968 brasileiro teve especificidades. Por exemplo, o nosso movimento estudantil, deflagrado a partir de março, seguiu uma dinâmica de luta específica e um calendário político próprio, anterior ao famoso maio de 1968 na França.

Do mesmo modo, as greves metalúrgicas de Osasco (região industrial na grande São Paulo, desencadeada em julho) e as greves de Contagem (região industrial na grande Belo Horizonte, Minas Gerais, deflagradas em abril e outubro do mesmo ano de 1968), encontram suas origens e raízes muito marcadas pela particularidade brasileira, em plena luta contra a ditadura militar.

Isso não significa dizer que os brasileiros não estivessem sintonizados com as manifestações que ocorreram mundo afora naquele ano. Havia uma série 
de aspectos comuns, intensificados pelo "clima político" existente no cenário mundial no ano de 1968. Podemos destacar, então, algumas condições estruturais que eram compartilhadas pelas diversas sociedades, em particular as "centrais", mas que se mostravam presentes nos chamados países do "Terceiro Mundo", como Brasil, México, Argentina etc. Em diferentes medidas, havia similaridade em condições como a industrialização avançada, a crescente urbanização e consolidação de modos de vida e cultura das metrópoles, a massificação dada pela indústria cultural, o aumento do proletariado e das classes médias assalariadas, a importância dos jovens na composição etária da população, o acesso crescente ao ensino superior, além da incapacidade do poder constituído para representar sociedades quese renovavam. Se esses condicionantes mais estruturais não explicam por si sós as ondas de rebeldia e revolução, ofereceram o solo onde floresceram as ações políticas e culturais diferenciadas que caracterizam o 1968 no Brasil. E, para compreendê-lo, é preciso lembrar de dois movimentos - relativamente distintos em suas origens, mas bastante articulados em sua processualidade: 0 movimento estudantil e as greves operárias.

\section{E o Movimento EstudantiL}

0 ano de 1968 teve início no Brasil com a eclosão de várias manifestações de estudantes. Eles reivindicavam ensino público e gratuito para todos, uma reforma que democratizasse o ensino superior e melhorasse sua qualidade, com maior participação estudantil nas decisões, mais verbas para pesquisa - voltada para resolver os problemas econômicos e sociais do Brasil. Os estudantes também contestavam a ditadura implantada com o golpe de 1964 e o cerceamento às liberdades democráticas. A maioria dos universitários estudava em escolas públicas e 0 acesso ao ensino superior era restrito, havendo uma procura muito maior que a oferta de vagas.

Desde 1966, a polícia da ditadura militar vinha reprimindo manifestações esporádicas estudantis nas ruas. Contudo, as rebeliões só viriam a desabrochar em 1968. Eram conhecidos como "excedentes" os estudantes que obtinham média nos vestibulares, mas não entravam na Universidade porque o número de vagas disponíveis era menor do que o de aprovados. No início do ano, eles se mobilizaram por mais vagas, ao passo que os freqüentadores do Calabouço - restaurante estudantil no Rio de Janeiro, cuja clientela era composta especialmente por estudantes secundaristas pobres - pleiteavam sua ampliação e melhoria do ensino 
público. Essas reivindicações específicas associavam-se à luta mais geral contra a política educacional e contra a própria ditadura militar vigente no Brasil desde 1964.

Em 28 de março de 1968, a polícia invadiu o restaurante Calabouço, gerando o primeiro grande conflito de rua daquele ano. Vários estudantes ficaram feridos e foi morto o secundarista Edson Luís de Lima Souto, cujo corpo foi levado para a Assembléia Legislativa do Rio de Janeiro. Passeatas de protesto espalharamse pelo resto do país onde, em Goiânia, a repressão policial matou mais um estudante.

Nos meses de abril e maio, houve novas manifestações públicas, mas os estudantes em geral buscaram refazer as forças, recolhendo-se no interior das faculdades. Ao mesmo tempo, esboçavam-se movimentos de contestação no movimento operário e em parcelas do sindicalismo brasileiro.

0 governador de São Paulo, Abreu Sodré, chegou a ser convidado pelo MIA (Movimento Intersindical Anti-Arrocho) que reunia comunistas e setores moderados e mesmo "pelegos" (denominação que caracteriza a liderança sindical conservadora que atuava dentro da estrutura sindical e está sempre subordinada e atrelada ao estado) para o comício de $1^{\circ}$ de maio na Praça da Sé, esperando obter algum respaldo popular para seu projeto de vir a tornar-se candidato à Presidente da República.

Ele e os dirigentes sindicais presentes, mais moderados, tiveram de refugiarse na Catedral da Sé, pois foram expulsos do palanque por grupos operários de Osasco e da região do $\mathrm{ABC}$ paulista, acompanhados por estudantes e militantes da esquerda de perfil mais crítico e à esquerda do Partido Comunista Brasileiro (PCB). Após queimar o palanque, os revoltosos saíram em passeata, gritando "só a luta armada derruba a ditadura”. De fato, vários dos presentes já pertenciam ou viriam a integrar-se às organizações que posteriormente enfrentaram a ditadura de armas na mão, realizando algumas ações armadas em 1968, que foram precursoras da escalada guerrilheira urbana que se expandiu nos anos seguintes no Brasil.

0 movimento estudantil ganharia novamente as ruas em junho de 1968, mês no qual atingiu seu ápice em todo o país. Generalizavam-se passeatas, greves, ocupações de faculdades etc. As divergências na cúpula do regime, indeciso entre a chamada "abertura" e o endurecimento ainda maior do cenário político nacional, foram exploradas pelo movimento estudantil. 0 Rio de Janeiro era o cenário principal, onde os estudantes logravam adesão popular para suas manifestações: 
mais de cem pessoas foram presas após sete horas de enfrentamento nas ruas no dia 19 de junho; as cenas repetiram-se no dia 21, ainda mais agravadas, deixando quatro mortos, dezenas de feridos e centenas de presos durante a "sexta-feira sangrenta".

A primeira de uma série de ocupações de escolas ocorreu no dia 22 de junho, na tradicional Faculdade de Direito de São Paulo, vinculada à USP (Universidade São Paulo), seguida pela Faculdade de Filosofia da mesma universidade. Protestos, manifestações, ocupações e passeatas ocorriam também em Belo Horizonte, Curitiba, Brasília, Salvador, Recife, Fortaleza, Porto Alegre, João Pessoa, Florianópolis, Natal, Belém, Vitória, São Luís e outros centros universitários.

A célebre Passeata dos Cem Mil teve lugar no dia 26 de junho: estudantes, intelectuais, artistas, religiosos e populares foram às ruas do Rio de Janeiro para protestar contra a ditadura e a repressão policial às manifestações. 0 governo não reprimiu a passeata devido à pressão da opinião pública. Uma Comissão ampla foi indicada para iniciar um diálogo com o governo, sem sucesso. Um impasse estava colocado ao movimento estudantil: as autoridades não faziam concessões e intensificavam a repressão. Enquanto isso, vários atentados terroristas eram praticados por uma organização paramilitar de extrema-direita, o Comando de Caça aos Comunistas (CCC), composto por estudantes e policiais de direita, financiados por grandes grupos capitalistas e com claro apoio da ditadura militar.

A repressão intensificou-se, atingindo também as lideranças do movimento estudantil. Vladimir Palmeira, o principal líder do Rio de Janeiro, foi preso em 3 de agosto de 1968. A Universidade de Brasília foi violentamente invadida pela polícia no dia 29. Em São Paulo, em 3 de outubro, foi assassinado um estudante na Faculdade de Filosofia, após ataque de estudantes e paramilitares de direita abrigados na Universidade Mackenzie, foco de organização dos setores estudantis conservadores. Seguiram-se passeatas e choques com a polícia nos dias subseqüentes, mas, ao mesmo tempo, começava a diminuir o número de passeatas e de participantes.

Em 15 de outubro, foi desmantelado o Congresso da União Nacional dos Estudantes (UNE), em Ibiúna, no interior paulista. Todos os presentes foram presos, cerca de 700 universitários, selando a derrota do movimento estudantil brasileiro de 1968. Vários de seus integrantes passariam, então, a concentrar suas atividades na militância política clandestina contra a ditadura, em organizações 
de esquerda, vinculados inclusive à luta armada que se desencadeou nos anos seguintes.

$\mathrm{Na}$ época, a contestação radical à ordem estabelecida difundia-se socialmente também no cinema, no teatro, na música popular, na literatura e nas artes plásticas. Nos anos 60, manifestações culturais diferenciadas cantavam em verso e prosa a esperada "revolução brasileira", que deveria basear-se na ação das massas populares, em cujas lutas a intelectualidade de esquerda pretendia engajar-se e mesmo liderar.

De modo resumido, dois grandes campos dividiam os artistas contestadores em 1968: o dos vanguardistas e o dos nacionalistas. Estes estavam mais próximos do PCB e procuravam desenvolver uma luta nacional-popular que abrisse caminho para uma posterior ação socialista. Os vanguardistas - liderados pelo movimento tropicalista de Caetano Veloso e Gilberto Gil - criticavam o nacionalpopular, buscando sintonizar-se com as vanguardas norte-americanas e européias, particularmente com a contracultura, incorporando-as à cultura brasileira. Apesar das divergências e das rivalidades entre eles, os artistas engajados nos dois campos viriam a sofrer perseguições, censura a suas obras e até mesmo prisão e exílio.

\section{E O MOVIMENTO OPERÁRIO}

Mas houve também uma outra figura social presente neste ciclo das rebeliões mundiais em 1968: o operário-massa, parcela hegemônica do proletariado da era do taylorismo/fordismo, dominante do capitalismo desde os anos 1920, tanto no cenário europeu, quanto em tantas outras partes do mundo. No Brasil, desde 1930 foram introduzidas estas práticas tayloristas e fordistas que impulsionaram o ciclo de industrialização nascente. E, com ele, deslanchava também a proletarização e a massificação dos trabalhadores brasileiros.

Nos países centrais, de industrialização avançada, com a perda da identidade cultural oriunda da era artesanal e manufatureira, o operário industrial se ressocializava de modo particular, quer pela parcelização da produção industrial e de serviç̧os, quer pela perda da destreza anterior ou ainda pela desqualificação repetitiva de suas atividades, além das formas de sociabilização ocorridas fora do espaço da fábrica. Essa nova forma de sociabilidade operária, segundo Alain Bihr, gerou as bases para a emergência de uma nova identidade e de uma nova forma de consciência de classe. 
Se o operário-massa foi a base social para a expansão do "compromisso" socialdemocrático anterior, foi também um claro elemento de ruptura e confrontação com a ordem dominante, questionando os pilares constitutivos da sociabilidade do capital, particularmente no que concerne ao controle social da produção, através de ações que não pouparam nenhuma das formações capitalistas desenvolvidas (BIHR, 1991).

0 boicote e a resistência ao trabalho despótico assumiam, entretanto, modos diferenciados e particularizados, marcados pelos distintos países e diferentes realidades. Desde as formas individualizadas do absenteísmo, da fuga do trabalho, do turnover, até o exercício de formas coletivas de ação visando a conquista do poder sobre o processo de trabalho, através de greves parciais, operações de zelo (marcados pelo "cuidado" especial com o maquinário, que diminuía o tempo/ ritmo de produção), contestações da divisão estrutural hierárquica do trabalho e do despotismo fabril emanado pelos quadros da gerência, formação de conselhos, propostas de controle auto-gestionárias, combate ao sindicalismo tradicional, chegando inclusive a lutar pelo controle social da produção e emergência do poder operário (Idem).

Estas lutas sociais a partir do espaço produtivo agregavam um componente explosivo à crise estrutural do sistema capitalista, ajudando a obstar a permanência do ciclo expansionista do capital, vigente desde o pós II Guerra; além do esgotamento econômico do ciclo de acumulação, as lutas de classes ocorridas em 1968 solapavam o domínio do capital pela base e afloravam as possibilidades de uma hegemonia (ou uma contra-hegemonia) oriunda do mundo do trabalho.

Estampavam, desse modo, seu descontentamento em relação à alternativa social-democrata, predominante nos sindicatos e partidos que reivindicam a representação das forças sociais do trabalho e que seguiam uma via predominantemente negocial, institucional e contratualista, dentro dos marcos do "compromisso socialdemocrático".

Se este traço esteve presente nas lutas operárias na França de 1968 e, no ano seguinte, no "Outono Quente" na Itália ou ainda no Cordobazo, rebelião operária na cidade de Córdoba, na Argentina, dentre tantos outros países, no Brasil as greves operárias deflagradas em 1968 tinham um claro sentido de confronto, tanto à ditadura militar que cerceava a liberdade e autonomia sindicais, quanto à sua política econômica fundada na superexploração do trabalho. 
Foram, neste sentido, uma primeira resposta dos trabalhadores ao golpe militar de 1964, quando se desencadeou uma profunda repressão sobre a esquerda, especialmente ao PCB e ao sindicalismo sob sua hegemonia. A repressão ao movimento operário e sindical era condição necessária para que o golpe militar de 1964 pudesse criar novos condicionantes para a expansão capitalista e sua maior internacionalização no Brasil.

Fortemente repressiva contra o movimento sindical, operário e popular, a ditadura militar brasileira decretou a ilegalidade de todos os partidos políticos, criando somente dois oficiais. Interveio em diversos sindicatos, proibiu a deflagração de greves, decretou a ilegalidade do CGT (Central Geral dos Trabalhadores), da UNE (União Nacional dos Estudantes), dos PCB e demais partidos de esquerda, iniciando-se um período difícil para o movimento operário no Brasil.

Depois de alguns anos de resistência, foi nos inícios de 1968 que a luta operária voltou com mais força e ofensividade. Em abril, setores sindicais à esquerda do Partido Comunista Brasileiro, lideraram uma greve em Contagem, cidade industrial próxima a Belo Horizonte, que teve um resultado positivo, uma vez que a ditadura militar acabou fazendo concessões frente às reivindicações trabalhistas, ao ser surpreendida pelo ressurgimento do movimento operário, silenciado e reprimido desde o golpe de 1964. Foi, então, a primeira vitória de uma greve operária depois de 1964. Organizados em Contagem e em Osasco, articulavam-se novos núcleos de esquerda, principalmente vinculados aos movimento operário católico de esquerda e militantes e simpatizantes de organizações políticas mais radicalizadas e críticas, à esquerda do PCB.

Os setores mais moderados do sindicalismo também se organizavam, através do Movimento Intersindical Anti-arrocho. Mas foi no mês de julho de 1968, em Osasco, cidade industrial da Grande São Paulo, que os operários fizeram uma greve legendária. Na época, Osasco era considerado um pólo central destes movimentos mais à esquerda, dada a atração exercida pela oposição sindical que se tornou vitoriosa nas eleições de 1967, para a direção do Sindicato dos Metalúrgicos.

Com José Ibrahim eleito para a direção sindical, a greve foi desencadeada. 0 resultado, entretanto, foi diferente de Contagem. Preparado para o confronto, a ditadura militar reprimiu duramente a paralisação, uma vez que estava decidida a não fazer mais nenhuma concessão. 0 movimento grevistafoi duramente reprimido e os dirigentes sindicais mais combativos exilaram-se do país, ou passaram a 
atuar na clandestinidade e posteriormente aderiram às distintas organizações de esquerda que participaram da luta armada contra a ditadura militar.

Fazendo um balanço autocrítico posterior do movimento, disse José Ibrahim, o principal líder da greve: partíamos da análise, de que "o Governo estava em crise, ele não tinha saída, o problema era aguçar o conflito, transformar a crise política em crise militar. Dai vinha nossa concepção insurrecional de greve. 0 objetivo era levar a massa, através de uma radicalização crescente, a um conflito com as forças de repressão. Foi essa concepção que nos guiou quando, em julho de 1968, decidimos desencadear a greve" (IBRAHIM, 1980).

Antecipando-se à greve geral que se indicava para outubro de 1968, época do dissídio coletivo dos metalúrgicos, a direção sindical de Osasco visualizava a possibilidade de estendê-la para outras regiões do país. Iniciada no dia 16 de julho, com a ocupação operária da Cobrasma, a greve atingiu as empresas Barreto Keller, Braseixos, Granada, Lonaflex e Brown Boveri. No dia seguinte o Ministério do Trabalho declarou a ilegalidade da greve e determinou a intervenção no Sindicato e as forças militares passaram a controlar todas as saídas da cidade de Osasco, além do cerco e a invasão das fabricas paralisadas.

A partir de então, desestruturou-se toda e qualquer possibilidade de manutenção e ampliação da greve. No seu quarto dia os operários retornaram ao trabalho e encerravam a greve. Estava derrotada a mais importante greve até então deflagrada contra a ditadura militar.

Em Contagem outra greve foi desencadeada no mês de outubro de 1968, animados com a vitória da greve anterior de abril, na mesma cidade, reivindicando melhores condições de trabalho e recusando o arrocho salarial. Mas o contexto da ditadura militar era de claro recrudescimento. A paralisação durou somente poucos dias e a repressão foi violenta sobre os grevistas, tendo o Sindicato sofrido intervenção, com a conseqüente destituição da sua direção. Ocorria, então, outra violenta derrota para o movimento operário, que levou anos para se recuperar. A ação operário-estudantil fora duramente reprimida pela ditadura militar, encerrando o 1968 brasileiro.

Mas a luta pela criação de comissões de fábricas, contra o despotismo fabril, contra a superexploração do trabalho, contra a estrutura sindical atrelada ao estado e em clara confrontação à ditadura militar no Brasil tinha deixado sólidas raízes, que ressurgiram, de outra forma e de outro modo, dez anos depois. 


\section{O Desfecho da Crise}

Em 13 de dezembro de 1968, a ditadura militar acentuou sua face ainda mais repressiva: decretou o Ato Institucional número 5 (AI-5), conhecido como "o golpe dentro do golpe". Oficializou-se o terrorismo de Estado, que prevaleceria até meados dos anos 70. 0 Congresso Nacional e as Assembléias Legislativas estaduais foram colocados temporariamente em recesso e o governo passou a ter plenos poderes para suspender direitos políticos dos cidadãos, legislar por decreto, julgar crimes políticos em tribunais militares, cassar mandatos eletivos, demitir ou aposentar juízes e outros funcionários públicos etc. Simultaneamente, generalizavam-se as prisões de oposicionistas, o uso da tortura e do assassinato, em nome da manutenção da "segurança nacional", considerada indispensável para o "desenvolvimento" da economia, do que se denominaria mais tarde "milagre brasileiro".

Inúmeros estudantes, operários, intelectuais, políticos e outros oposicionistas dos mais diversos matizes foram presos, cassados, torturados, mortos ou forçados ao exílio, após a edição do AI-5. Rígida censura foi imposta aos meios de comunicação e às manifestações artísticas. 0 regime militar dava fim à luta política e cultural do período, reprimindo duramente qualquer forma de oposição. "Anos de chumbo" viriam a suceder o "ano rebelde" de 1968.

Como se vê, o 1968 brasileiro integrou a onda de revoltas mundiais, mas não deve ser compreendido fora do contexto específico nacional, de luta contra a ditadura e afirmação de interesses de estudantes, dos operários, das classes médias intelectualizadas e outros setores de oposição.

Já se afirmou, com propriedade, que os acontecimentos históricos de 1968 não devem ser mistificados, mas sua importância não pode ser minimizada. Ainda são discutidas a extensão e a profundidade das marcas deixadas na História pelas contestações daquele ano emblemático, sem que se chegue a conclusões unívocas. Os movimentos de 1968 prometiam construir um novo mundo, mas os grilhões do passado viriam a mostrar-se muito mais pesados do que os militantes de 1968 supunham - a ponto de vários ativistas da época passarem para o campo conservador vitorioso, chegando a ocupar cargos importantes em governos que adotam medidas neoliberais em várias partes do mundo e também no Brasil.

Como conclusão, diríamos que os dois principais exemplos que caracterizam o ano de 1968 no Brasil tiveram muitas similitudes: ambos estavam à esquerda dos movimentos mais tradicionais e propugnavam (justamente) uma 
alternativa ao PCB e sua política de moderação, dominante no pré-64, tanto no movimento operário, quanto no movimento estudantil. Mas as lutas estudantis e operárias de 1968 no Brasil não conseguiram tornar viável uma alternativa de massas, exaurindo-se em seu vanguardismo.

0 movimento estudantil, derrotado, engrossou as fileiras da luta armada contra a ditadura militar através de várias de suas lideranças e militantes. 0 movimento operário, depois das derrotas de Contagem e Osasco, refluiu fortemente e teve também vários de seus quadros mais à esquerda incorporados à luta armada. Ambos desnudaram o sentido profundamente ditatorial e terrorista do Estado brasileiro e foram, por isso, violentamente reprimidos. Ainda que suas lógicas tivessem causalidades distintas e particulares, ambos tiveram o predomínio das forças de extrema esquerda que recusavam a política de moderação, frente ampla e colaboração de classes defendida especialmente pelo PCB.

Não foi, então, por acaso que em Osasco e Contagem pudemos presenciar uma ação operária com significativa presença estudantil, especialmente através dos estudantes/militantes de organizações de esquerda que ingressavam nas fileiras da vanguarda operária para melhor influenciar as ações dos trabalhadores.

Talvez esse seja um traço marcante do ano de 1968 no Brasil, muito diferente, tanto do movimento que eclodiu dez anos depois, com as greves metalúrgicas do $\mathrm{ABC}$ paulista - lideradas por Luiz Inácio Lula da Silva -, quanto do movimento estudantil que voltou a tomar as ruas de várias cidades brasileiras na segunda metade dos anos 1970, novamente lutando contra a ditadura militar. Mas esta já é outra história.

\section{REFERÊNCIAS}

ANTUNES, Ricardo. Les luttes sociales dans la sphère du travail au Brésil. Quelques défis passés et présents - L’Amérique Latine em Lute: hier \& aujourd hui. Actuel Marx, n. 42, Paris, 2007.

BIHR, Alain. Du "grand soir" à l'alternative: le mouvement ouvrier européen en crise. Paris: Les Editions Ouvrieres, 1991.

GORENDER, Jacob. Combate nas trevas: a esquerda brasileira - das ilusões perdidas à luta armada. São Paulo: Ática, 1987. 
IBRAHIM, José. Movimento operário: novas e velhas lutas (debate). Revista Escrita/Ensaio. São Paulo: Ed. Escrita, 1980.

MARTINS FILHO, João Roberto. Movimento estudantil e ditadura militar: 19641968. Campinas: Papirus, 1987.

REIS, Daniel Aarão e MORAES, Pedro de (org.). 1968, a paixão de uma utopia. Rio de Janeiro: Espaço e Tempo, 1988.

RIDENTI, Marcelo. Em busca do povo brasileiro: artistas da revolução. Rio de Janeiro: Record, 2000.

SCHWARZ, Roberto. Remarques sur la culture et la politique au Brésil, 1964-1969. Les Temps Modernes, n.288, Paris, juillet, 1970. 